\title{
Implementasi Kurikulum 2013: MOODLE (Modular Object Oriented Dynamic Learning Environment) dalam Pembelajaran Fisika melalui Lembar Kerja Siswa pada Materi Optik di SMA
}

\author{
Pandu Joyo Sampurno, Rizky Maulidiyah, Hidayah Zuliana Puspitaningrum \\ Universitas Jember \\ Jalan Kalimantan 37 Tegalboto Jember, 68121. \\ Pandujoy23@gmail.com
}

\begin{abstract}
Abstrak - Perkembangan teknologi menuntut dunia pendidikan terus meningkatkan mutu penggunaan teknologi informasi dalam pembelajaran. Media pembelajaran berbasis teknologi komputer seperti moodle merupakanmedia belajar untuk diaplikasikan sesuai tuntutan kurikulum 2013. Moodle merupakan model tempat belajar dinamis berorientasi objek yang berbasis web. Pengaplikasian moodle dapat membantu siswa mendapatkan tambahan pengetahuan berupa: (1) Materi pembelajaran optik di upload melalui fitur moodle; (2) Lembar Kerja Siswa (LKS) yang inovatif dan meningkatkan kemandirian siswa sesuai tuntutan kurikulum 2013.Jenis penelitian yang digunakan adalah Research and Development $(R \& D)$, yaitu penelitian dan pengembangan.Metode penelitian dan pengembangan adalah metode penelitian yang digunakan untuk menghasilkan produk tertentu, dan menguji keefektivan produk tersebut. Tujuan dari penelitian adalah mengembangkan Lembar Kerja Siswa (LKS) pada pembelajaran fisika pada materi optik melalui moodle berbasis e-learning sebagai upaya inovatif untuk mendukung implementasi kurikulum 2013.
\end{abstract}

Kata kunci : Lembar Kerja Siswa (LKS), moodle, kurikulum 2013.

Abstrac- Technology development demanding education world continue to improve the quality of the use of information technology in learning. Instructional media-based computer technology such as Moodle is a learning medium to be applied according to the demands of the curriculum in 2013. Moodle is a learning model of a dynamic object-oriented web based. Moodle application can help students gain additional knowledge in the form of: (1) optical learning materials uploaded through moodle features; (2) Student Worksheet (LKS) innovative and increase the independence of students according to the demands of the curriculum in 2013. This type of research is the Research and Development $(R$ $\& D)$, namely research and development. This method is a method of research used to produce a particular product, and test the effectiveness of these products. The aim of the research is to develop students' worksheet (LKS) on learning physics in optical materials via Moodle-based e-learning as an innovative effort to support the implementation of the curriculum in 2013.

Keywords :Student Worksheet (LKS), Moodle, the curriculum in 2013.

\section{I.PENDAHULUAN}

Perkembangan dunia pendidikan di era globalisai saat ini mendapatkan pengaruh besar dari perkembangan teknologi informasi.Tuntutan perkembanganteknologimenuntut dunia pendidikan terus mengalami peningkatan mutu terutama penyesuaian penggunaan teknologi informasi dalam proses pembelajaran.Pembelajaran berbasis web merupakan suatu kegiatan pembelajaran yang memanfaatkan media situs (website) yang dapat diakses melalui jaringan internet.Pembelajaran berbasis web atau web based learning merupakan jenis penerapan dari pembelajaran elektronik. Pembelajaran elektronik yang dikenal dengan sebutan e-learning ini membawa pengaruh terjadinya proses transformasi pendidikan konvensional ke dalam bentuk digital, baik secara isi maupun sistemnya.elearning adalah proses instruksi yang melibatkan penggunaan peralatan elektronik dalam menciptakan, membantu perkembangan, menyampaikan, menilai dan mempermudah suatu proses belajar mengajar peserta didik sebagai pusatnya yang dilakukan secara interaktif kapanpun dan dimanapun [1].Kecenderungan untuk mengembangkan $e$-Learning sebagai salah satu alternatif pembelajaran di berbagai lembaga pendidikan dan pelatihan semakin meningkat sejalan dengan perkembangan di bidang teknologi komunikasi dan informasi[2].Pemanfaatan teknologi informasi untuk kegiatan pembelajaran di Indonesia semakin kondusif dengan diterbitkannya Surat Keputusan Menteri Pendidikan Nasional (SK Mendiknas) nomor 107/U/2001 yang mendorong sekolahkonvensional untuk menyelenggarakan pendidikan jarak jauh (dual mode). Hal ini memberikan kemudahan kepada guru maupun siswa yang memiliki keterbatasan jarak dan waktu, untuk tetap melakukan kegiatan pembelajaran melalui elearning.

Pengembangkan media pembelajaran berbasis teknologi komputer atau e-learning seperti moodle merupakan pengembangan media belajar yang tepat untuk diaplikasikan sesuai dengan tuntutan kurikulum 2013. Moodle (Modular Object Oriented Dynamic Learning Environment) yang berarti tempat belajar dinamis dengan menggunakan model berorientasi objek atau merupakan paket lingkungan pendidikan berbasis web yang dinamis.Moodle merupakan perangkat lunak open source yang mendukung implementasi e-learning dengan paradigma terpadu dimana berbagai fitur penunjang pembelajaran dengan mudah dapat diakomodasi dalam suatu portal e-learning [3]. Moodle berfungsi sebagai alat bantu yang efektif dalam 
menyediakan fasilitas pembelajaran karena dilengkapi dengan fitur-fitur penting penunjang pembelajaran seperti tugas, quiz,chat, kolaborasi, serta fitur utama yang dapat meng-upload berbagai format materi pembelajan serta lebih mudah untuk dipahami karena informasi yang di sajikan tidak hanya berbentuk tulisan tetapi juga gambar dan video [4].

Proses pembelajaran pada kurikulum 2013 menempatkan mata pelajaran TIK sebagai sarana pembelajaran pada semua mata pelajaran yaitu terintegrasi dalam semua mata pelajaran. Hal ini sesuai dengan paparan Menteri Pendidikan dan Kebudayaan Republik Indonesia (Mendikbud RI) tentang pengembangan Kurikulum 2013, guru diharapkan melek informasi, melek media dan melek TIK. TIK memiliki peranan yang cukup strategis dalam sebagai keahlian dan kompetensi. maksudnya, penggunaan TIK harus proporsional atau TIK sektor pendidikan, di antaranya: (1) TIK bisa masuk ke semua lapisan masyarakat tapi sesuai dengan porsinya masing-masing; (2) TIK sebagai sumber bahan belajar. Hal ini mengenai buku dan bahan belajar yang diperbaharui secara kontiniu dengan menggunakan teknologi. karena tanpa teknologi, pembelajaran yang upto-datemembutuhkan waktu yang cukup lama; (3) TIK sebagai alat bantu dan fasilitas pembelajaran [5].

Materi alat-alat optik di SMA memerlukan pemahaman lebih dalam mempelajarinya, sehingga membutuhkan waktu tambahan diluar jam pelajaran.Pengaplikasian moodle dapat membantu siswa mendapatkan tambahan pengetahuan berupa : (1) Materi pembelajaran optik melalui video atau modul yang di upload melalui fitur pada moodle; (2) Lembar Kerja Siswa (LKS) yang inovatif dan mampu meningkatkan kemandirian siswa sesuai dengan tuntutan kurikulum 2013. Media pembelajaran sebagai sumber informasi berbentuk bahan cetak/ buku, majalah, LKS, dan sejenisnya yang dapat digunakan sebagai penunjang proses pembelajaran dalam menyajikan atau menyerap mata pelajaran. Salah satu sumber belajar yang dianggap mampu dalam proses pembelajaran adalah LKS. Lembar kerja siswa dapat berfungsi sebagai alternatif media pembelajaran. LKS termasuk media cetak hasil pengembangan teknologi cetak yang berupa buku dan berisi materi visual [6]. Keberadaan LKS memberi pengaruh yang cukup besar dalam proses belajar mengajar, sehingga penyusunan LKS harus memenuhi berbagai persyaratan yaitu syarat didaktik, syarat konstruksi, dan syarat teknik [7]. LKS bertujuan untuk membantu siswa belajar secara terarah dan dapat berfungsi sebagai pegangan guru selain buku pegangan lainnya. Penyajian LKS meliputi kegiatan yang melibatkan siswa secara aktif seperti percobaan sederhana, diskusi dan latihan soal.

Strategi penggunaan moodle dalam proses pembelajaran dapat membantu guru ketikatidak dapat memberikan pemantapan materi kepada siswa, pemantapan materi ini berupa Lembar Kerja Siswa (LKS) yang dapat di unduh pada fasilitas yang telah disediakan pada moodle. LKS yang telah dikerjakan oleh siswa dapat memiliki keterampilan mandiri yang sesuai dengan tuntutan kurikulum 2013. Adapun tujuan dari penelitian ini adalah mengembangkan Lembar Kerja Siswa (LKS) pada pembelajaran fisika pada materi optik melalui moodle berbasis e-learning sebagai upaya inovatif untuk mendukung implementasi kurikulum 2013.

\section{LANDASAN TEORI}

\section{A. Pembelajaran Fisika}

Pembelajaran sains termasuk fisika, lebih menekankan pada pemberian pengalaman langsung untuk mengembangkan kompetansi, agar siswa mampu menjelajahi dan memahami alam sekitar secara alamiah. Pendidikan sains diarahkan untuk mencari tahu dan berbuat sehingga dapat membantu siswa untuk memperoleh pemahaman yang lebih mendasar tentang alam sekitar [8].

Dalam pembelajaran fisika, kemampuan peserta didik dalam untuk dapat Memecahkan persoalan dan bertindak yaitu melakukan observasi, bereksperimen, mendiskusikan suatu persoalan, memperhatikan demonstrasi, menjawab pertanyaan dan menerapkan konsep-konsep dan hukum- hukum untuk memecahkan persoalan terhadap hal yang dipelajari, serta mengkomunikasikan hasilnya[9].

\section{B.Lembar Kerja Siswa}

LKS merupakan salah satu bahan ajar yang penting untuk tercapainya keberhasilan dalam pembelajaran fisika. Lembar kerja siswa (LKS) yaitu materi ajar yang sudah dikemas sedemikian rupa, sehingga siswa diharapkan dapat mempelajari materi ajar tersebut secara mandiri[10]. LKS juga merupakan media pembelajaran, karena dapat digunakan secara bersama dengan sumber belajar atau media pembelajaran yang lain. LKS menjadi sumber belajar dan media pembelajaran tergantung pada kegiatan pembelajaran yang dirancang[11].

LKS yang baik, harus memenuhi berbagai persyaratan, yaitu persyaratan dikdatik, persyaratan konstruktif, dan persyaratan teknik. Langkah-langkah aplikatif membuat LKS yaitu: 1) melakukan analisis kurikulum; 2) menyusun peta kebutuhan LKS; 3) menentukan juduljudul LKS; 4) penulisan LKS [12].

\section{Moodle}

Moodle merupakanjalan menuju pendidikan tanpa batas dan merupakan aplikasi yang dapat mengubah sebuah media pembelajaran ke dalam bentuk web. Moodle juga merupakan sebuah course management system yang digunakan untuk membuat sebuah proses belajar (learning) bisa dilakukan secara online, powerful dan fleksibel [13].

Moodle (Modular Object Oriented Dynamic Learning Environment) merupakan rancangan software untuk kegiatan pembelajaran berbasis internet dan website yang dapat digunakan secara bebas sebagai produk open source [14]. Sistem e-learning berbasis open source dapat meningkatkan efisiensi serta efektivitas kinerja pengajar dan pemahaman pembelajar terhadap materi pembelajaran. Moodle memberikan paket software yang lengkap meliputi Apache, MySQL, dan PHP [15]. Dengan menggunakan LMS Moodle yang digunakan dalam e-learning penilaian hasil pembelajaran dapat dilakukan secara online (ujian online) [16]. 


\section{III.METODE PENELITIAN}

Penelitian ini termasuk penelitian Research and Development (R \& D), yaitu penelitian dan pengembangan. Metode penelitian dan pengembangan atau dalam bahasa inggrisnya Research and Development adalah metode penelitian yang digunakan untuk menghasilkan produk tertentu, dan menguji keefektivan produk tersebut [17].Pada penelitian ini produk yang dihasilkan adalah LKS berbasis ICT dengan LSM Moodlepada pembelajaran Fisika materi Optik untuk Mencapai Kompetensi Siswa Kelas X SMA.

Pada penelitian ini terdapat satu objek penelitian, yaitu LKS berbasis ICT dengan LSM Moodlepada pembelajaran Fisika materi Optikuntuk mencapai kompetensi siswa yang diujicobakan pada siswa kelas X semester 2 SMAN 4 Jember.LKS yang dibuat oleh peneliti divalidasi oleh dosen jurusan Fisika sebagai tenaga ahli dan guru Fisika sebagai praktisi. Berdasarkan kelemahan-kelemahan yang ditemukan saat validasi, maka dilakukan perbaikan menurut saran dari validator.LKS yang telah direvisi diujicobakan dalam bentuk uji coba terbatas.

Prosedur penelitian ini mengacu kepada panduan penelitian pengembangan (Research and Depelopment) sebagaimana yang diungkapkan Sugiyono [18]. Langkahlangkah dalam penelitian ini meliputi mengenal potensi dan masalah, mengumpulkan informasi, mendesain produk, memvalidasi desain, merevisi desain, menguji coba produk, dan merevisi produk. Prosedur penelitian tersebut menjadi acuan dalam memperoleh temuan penelitian dan kesimpulan penelitian.

Validasi desain dibutuhkan untuk mengetahui apakah produk yang dirancang valid atau tidak. Validitas desain produk dilakukan oleh dosen sebagai tenaga ahli dan guru sebagai praktisi.Komponen penilaian tersebut meliputi substansi materi, tampilan komunikasi visual, desain pembelajaran, dan pemanfaatan software.

Hasil belajar siswa pada ranah kognitif diperoleh dengan memberikan pretes dan postes. Hal ini diperlukan untuk menentukan keefektivan LKS berbasis ICT yang digunakan dalam proses pembelajaran. Pretes diberikan kepada siswa sebelum diberikan pelakuan. Postes diberikan kepada siswa setelah perlakuan LKS berbasis ICT pada pembelajaran Fisika materi Optik.

Teknik analisis data berkenaan dengan perhitungan untuk menjawab perumusan masalah dan pengujian hipotesis yang diajukan. Pada penelitian ini digunakan tiga macam teknik analisis data, yaitu analisis validasi, analisis kepraktisan, dan analisis efektivitas.

\section{IV.HASIL PEMBAHASAN}

Pola perilaku siswa dapat ditentukan dari pola pembelajaran. Pembelajaran merupakan kegiatan yang dilakukan oleh guru untuk menciptakan proses interaksi antar sesama siswa, guru dengan siswa, dan siswa dengan sumber belajar. Selama kegiatan pembelajaran, tugas guru yang paling utama adalah mengkondisikan lingkungan belajar agar menunjang terjadinya perubahan perilaku bagi siswa. Pola hubungan pembelajaran adalah dalam rangka emansipasi diri siswa menuju kemandirian, dimana proses belajar untuk meningkatkan kemampuan kognitif, afektif, dan psikomotorik bagi diri siswa.Pembelajaran perlu memiliki sifat-sifat tertentu. Menurut Kemendikbud "Pembelajaran bersifat (1) holistik, (2) bermakna, (3) otentik, dan (4) aktif'.

Setelah dilakukan proses pembelajaran, maka perlu dilakukan penilaian untuk melihat apakah proses pembelajaran yang dilakukan berhasil dengan pencapaian kompetensi dan perubahan tingkah laku. Penilaian hasil belajar digunakan untuk menilai kompetensi siswa, bahan penyusun laporan kemajuan hasil belajar dan memperbaiki proses pembelajaran. Penilaian yang dilakukan guru hendaklah bersifat berkelanjutan dan objektif terhadap siswanya, sehingga ketiga ranah hasil belajar dapat dipantau sekaligus dalam kegiatan proses pembelajaran yang dilaksanakan guru.

Berdasarkan keunggulan yang disampaikan, peneliti membuat dan menerapkan LKS berbasis ICT dengan LSM Moodlepada pembelajaran Fisika materi Optik menurut standar proses. Produk yang dihasilkan melalui penelitian R\&D dapat meningkatkan produktivitas pendidikan, yaitu produk yang unggul dalam hal kualitas dan kuantitas serta relevan dengan kebutuhan. Dalam penelitian ini produk yang dikembangkan berupa bahan ajar non printed yaitu LKS berbasis ICT dengan LSM Moodle pada pembelajaran Fisika materi Optik yang diharapkan dapat meningkatkan kualitas pembelajaran Fisika siswa kelas X di SMAN 4Jember. Kerangka LKS berbasis ICT dengan LSM Moodle yang dihasilkan mengacu pada kerangka LKS yang dikeluarkan oleh juknis KTSP 2010. Struktur menu dari LKS berbasis ICT dengan LSM Moodle meliputi:

a. Home, berisi perkenalan singkat tentang LKS berbasis ICT dengan LSM Moodle dan petunjuk penggunaan LKS ini agar siswa dapat menggunakannya dengan mudah.

b. Pendahuluan, berisi perkenalan singkat tentang LKS berbasis ICT dengan LSM Moodle, cakupan SK, cakupan $\mathrm{KD}$,dan petunjuk cara penggunaan LKS berbasis ICT ini.

c. LKS, menu ini berisi halaman LKS berbasis ICT dengan dengan LSM Moodle. LKS berbasis ICT ini juga di dalamnya diselipkan beberapa video, animasi dan gambar. Siswa diharapkan dapat menimbulkan pemahaman mereka dan menggali lebih dalam terhadap konsep Fisika.

d. Evaluasi, berisi soal-soal yang bertujuan untuk melatih siswa memecahkan permasalahan dan menguji kemampuan mereka dalam memahami materi sebelumnya.

e. Download, memberikan kesempatan kepada siswa untuk mendownload LKS serta soal yang terdapat dalam LKS.

f. Chatting, menu ini memfasilitasi siswa untuk berdiskusi dengan guru dan antar siswa tentang materi yang dibahas.

g. Forum Diskusi, menu ini memfasilitasi siwa untuk berdiskusi antar siswa dan siswa dengan guru.

Hasil penelitian menunjukkan dua hasil utama temuan dari penelitian ini. Kedua hasil utama temuan penelitian adalah: 1.Validitas dan deskripsi LKS Fisika berbasis ICT dengan LSM Moodleuntuk pembelajaran Fisika 
menurut standar proses pada siswa SMA kelas X, 2. Kepraktisan dan efektivitas penggunaan LKS Fisika berbasis ICT dengan dengan LSM Moodle untuk pembelajaran Fisika menurut standar proses pada siswa SMA kelas X.Berdasarkan validasi oleh tenaga ahli dapat disimpulkan bahwa produk yang dihasilkan adalah valid untuk digunakan dalam proses pembelajaran Fisika SMA. Komponen penilaian tersebut meliputi substansi materi, tampilan komunikasi visual, desain pembelajaran, dan pemanfaatan software.

LKS berbasis ICT ini dibuat dengan desain LKS yang disusun meliputi menu: Home, Pendahuluan, LKS, Evaluasi, Download, Chatting, dan Forum diskusi. LKS ini dibuat dengan software moodle. Halaman yang dibuat pada LKS tersebut dibuat terlebih dahulu pada microsoft word pada Gambar 1:

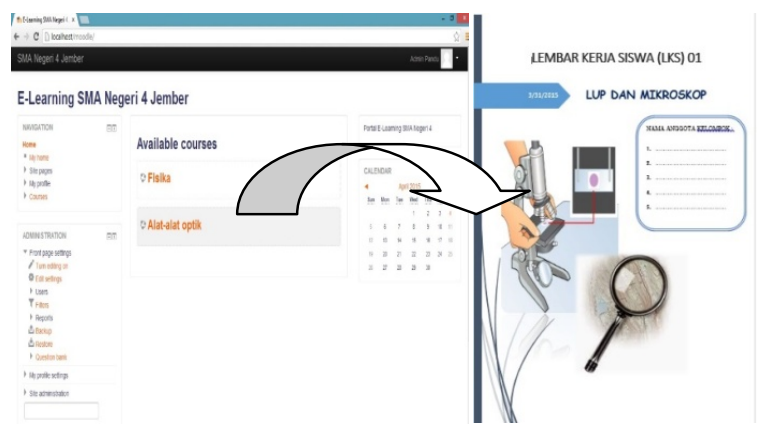

Gambar 1. Tampilan awal produk LKS berbasis ICT

Halaman utama memberikan gambaran umum pada pengguna tentang LKS berbasis ICT. Pada halaman utama pengguna dapat mengetahui menu utama pada LKS. Menu utama LKS meliputi: home, pendahuluan, LKS, evaluasi, dan download, chatting dan Forum Diskusi. Selain itu terdapat deskripsi singkat mengenai LKS berbasis ICT.

\section{KESIMPULAN}

Berdasarkan hasil penelitian dan pembahasan yang telah dilakukan dapat dikemukakan beberapa kesimpulan sebagai berikut:

1. Validitas LKS Fisika berbasis ICT dengan LSM Moodle dalam pembelajaran siswa kelas X semester 2 menurut tenaga ahli dan praktisi masing-masing berada pada kategori valid. Hasil validasi juga menunjukkan deskripsi produk LKS baik. Masingmasing LKS dilengkapi dengan tugas pendahuluan dan tugas inti. Menu yang ada pada LKS terdiri dari home, pendahuluan, LKS, evaluasi, download, chatting, dan forum diskusi.;

2. Penggunaan LKS Fisika berbasis ICT dengan LSM Moodle dalam pembelajaran siswa kelas X semester 2 adalah praktis yang ditandai dengan nilai rata-rata kepraktisan siswa. Selain itu, penggunaan LKS Fisika berbasis ICT dengan LSM Moodle dinilai efektif dalam meningkatkan hasil belajar dan menumbuhkan nilai karakter mulia siswa dalam pembelajaran kelas $\mathrm{X}$ semester 2 .

\section{UCAPAN TERIMA KASIH}

Penelitian dan pengembangan yang telah dilakukan tidak terlepas dari kontribusi tenaga dan pikiran beberapa pihak. Oleh karena itu, peneliti mengucapkan terima kasih kepada Bapak Supeno, S. Pd, M.Si selaku dosen pembimbing dan teman-teman yang telah membantu dalam menyelesaikan penelitian ini.

\section{PUSTAKA}

[1] Prasojo, Lantip. (2011). Teknologi Informasi Pendidikan.Yogyakarta: Gava Media.

[2] Sutomo, E. 2012. E-learning sebagai alternatif model pembelajaran dalam upaya meningkatkan mutu di perguruantinggi. Jurnal Falasifa. Vol.3 No.1 hal 150.

[3] Pratiwi, Y. I., dkk. 2014.Pengembangan media pembelajaran ipa terpadu interaktif dalam bentuk moodle untuk siswa smp pada tema matahari sebagai sumber energi alternatif. Jurnal Pendidikan Fisika. Vol.2 No.1 hal 26.

[4] Safitri dkk. 2014. Pengembangan Media Pembelajaran Ipa Terpadu Interaktif Dalam Bentuk Moodle Untuk Siswa SmpPada Tema Hujan Asam. Jurnal Pendidikan Fisika. Vol.2 No.1

[5] Simanjuntak, D. 2013. Peranan Teknologi Informasi dan Komunikasi dalam Kurikulum 2013. Jurnal Pendidikan Penabur. No.21 hal 84.

[6] Hendro Darmodjo \& Jenny R.E Kaligis. 1992. Pendidikan IPA. Proyek Pembinaan Tenaga Kependidikan Direktorat Jenderal Pendidikan Tinggi Departemen Pendidikan dan Kebudayaan.

[7] Dwijananti, P.,pengembangan kemampuan berpikir kritis mahasiswa melaluiPembelajaran problem based instruction pada mata kuliah Fisika lingkungan, jurnal pendidikan fisika indonesia. Vol. 6 hal: 108-114.

[8] K, Dian E.,et.al.,Pengembangan Lembar Kerja Siswa (LKS) dengan Pendekatan Investigasi Kelompok guna Mmengoptimalkan Keterampilan Berkomunikasi dan Berpikir Kritis Siswa kelas XI SMA Negeri 2 Purworejo Tahun Pelajaran 2012/2013,Radiasi Vol 3 No 1, 2013.

[9] Damayanti, Dyah, S., pengembangan lembar kerja siswa (LKS) dengan pendekatan inkuiri terbimbing untuk mengoptimalkan kemampuan berpikir kritis peserta didik pada materi listrik dinamis sma negeri 3 purworejo kelas $\mathrm{x}$ tahun pelajaran 2012/2013, radiasi.vol.3.no.1.dyah shinta damayanti.

[10] Rohaeti, Eli, pengembangan lembar kerja siswa (lks) mata pelajaran sains kimia untuk smp, inovasi pendidikan jilid 10, nomor 1, mei 2009.

[11] Damayanti, Dyah S., et.al,Pengembangan Lembar Kerja Siswa (LKS) Dengan Pendekatan Inkuiri TerbimbingUntuk Mengoptimalkan Kemampuan Berpikir Kritis Peserta Didik pada Materi Listrik Dinamis SMA Negeri 3 Purworejo kelas $\mathrm{X}$ tahun pelajaran 2012/2013,RadiasiVol.3 no 1, 2013.

[12] Ismanto, Heru, Pembuatan aplikasi perkuliahan jarak jauh berbasis web menggunakan moodle pada universitas musamus merauke, prosiding snapp2012: sains, teknologi, dan kesehatan.

[13] Hanum N Sulistyo. 2013. The effectiveness of e-learning as instructional media(evaluation study of e-learning instructional model in smk telkom sandhyputra purwokerto). Jurnal Pendidikan Vokasi, Vol 3, No 1.

[14] Munir. 2009. Pembelajaran jarak jauh berbasis teknologi informasi dan komunikasi. Bandung: Alfabeta.

[15] Widikda Dkk. 2012. Evaluasi Pelaksanaan Ujian Online Dengan MenggunakanLearning Management System Moodle Pada Mata Kuliah PneumatikHidrolik. Surakarta: UNS. 
[16] Kasiram, Moh. (2008). Metodologi Penelitian. Malang : UIN-Malang Press.

[17] Sugiyono. (2012). Statistika Untuk Penelitian. Bandung: Alfabeta.

[18] Sugiyono. (2012). Metode Penelitian Pendidikan. Bandung: Alfabeta. 